\title{
Heterophil Measurement
}

National Cancer Institute

\section{Source}

National Cancer Institute. Heterophil Measurement. NCI Thesaurus. Code C116186.

The determination of the amount of heterophils present in a sample. 